\title{
Do patients get the best deal when antibiotics are prescribed out of hours?
}

Sunderland District General Hospital, Kayll Road, Sunderland, Tyne and Wear

K A Lark

C E Phillips

Correspondence to: Mr C E Phillips, Accident and Emergency Department, Dryburn Hospital, Durham DH1 5TW.

Accepted for publication 27 January 1997

\begin{abstract}
Objective-To investigate patients' compliance in obtaining follow on prescriptions after being prescribed a "starter pack" by the accident and emergency (A\&E) department, and to assess the cost of the starter pack system.

Methods-During a study period of two months, out of hours prescriptions of antibiotic starter packs in $A \& E$ were monitored prospectively to determine how many patients returned to the hospital pharmacy or to their general practitioner (GP) for the remainder of the prescribed course. Current costs of out of hours antibiotic prescriptions were calculated, as were the costs of providing a full course of antibiotics on the patient's first visit to the A\&E department.

Results-During the study period, 571 antibiotic items were prescribed as starter packs (three days' supply) to 437 patients. Of these, $232(53 \%)$ chose to return to the hospital and $175(40 \%)$ to their GP for the follow on prescription to complete their course. In 29 cases $(7 \%)$ the information was not recorded and those patients were excluded from analysis. Only $50 \%$ of patients electing to obtain the follow on prescription from their GP did so compared with $83.7 \%$ of those electing to return to the hospital pharmacy. Failure to obtain the follow on prescription was termed "late primary non-compliance". There was an estimated annual saving to the hospital of $£ 3131$ if the patients were given the full course of antibiotics at their primary attendance at $A \& E$.

Conclusions-Patients prescribed antibiotics out of hours should be dispensed full courses. This would eliminate late primary non-compliance at no extra cost to the health authority.

( $($ Accid Emerg Med 1997;14:159-162)
\end{abstract}

Keywords: antibiotics; compliance; out of hours prescribing

Many patients attending accident and emergency (A\&E) departments are prescribed drugs, usually antibiotics or analgesics, at a time when the hospital pharmacy is closed. $A \& E$ departments overcome this problem in different ways. Full courses can be prescribed from the $A \& E$ department either by issuing FP10 prescriptions which can be cashed at pharmacies outside the hospital or by directly dispensing a full course. The alternative is to issue starter packs, which contain enough tablets for the patients to take until they can obtain the remainder of the course with a follow on prescription. This prescription can be issued in the $A \& E$ department at the time of the first attendance, for dispensing in the hospital pharmacy during normal opening hours, or it can be an FP10 prescription issued by their general practitioner after a day or two.

Many A\&E departments use starter packs, but no information is available regarding patients' compliance in redeeming the follow on prescription, nor has there been an assessment of the cost implications of the starter pack system. This study was designed to answer these questions.

Over a two month period in the $A \& E$ department of a large district general hospital we investigated patients' primary compliance in obtaining follow on prescriptions after having been dispensed starter packs. In addition we have looked at the cost implications of changing from a starter pack system for out of hours prescribing to a system of directly dispensing a full course from the $A \& E$ department on the patient's first attendance.

\section{Methods}

The study was undertaken with adults attending the A\&E department at Sunderland District General Hospital which serves a population of 300000 . It sees 66000 new attendances each year, of which approximately half attend outside normal hospital pharmacy opening hours, which are from 8:30 am to 5:00 pm Monday to Friday, and 8:30 am to $12: 30$ pm on Saturdays.

The current procedure for out of hours dispensing is that starter packs are issued from the A\&E department which contain a three day supply of antibiotics. For the follow on prescription, the patient is given the option of either returning to the hospital pharmacy when it is next open with a hospital prescription issued from the A\&E department, or they can opt to visit their general practitioner for an FP10 prescription.

It is current practice that all drugs issued out of hours from the $A \& E$ department are recorded in a "take home drugs" book. In addition to this standard information, during the study period a record was made of whether the patient had been issued with a hospital prescription or whether they had opted to see their 
general practitioner. Prescriptions for antibiotics issued out of hours were selected to study the compliance rates for patients returning to the hospital pharmacy and those electing to see their general practitioner.

If hospital prescriptions were issued out of hours they were marked "OUT" by the medical staff. Prescriptions marked "OUT" dispensed at the hospital pharmacy established that these patients had complied. For those patients intending to return to the hospital pharmacy for their follow on prescription and who had not done so, non-compliance was confirmed by checking on the hospital computer that no prescription had been dispensed. The A\&E records for these patients were examined. Those who had attended for a review appointment were judged to have complied because either a follow on prescription was issued at the clinic or a medical decision was made not to continue the course. Patients who intended to return to the hospital pharmacy but had not done so and had not attended for a review appointment were regarded as non-compliers.

A letter written to the local general practitioners informed them of the project and asked them to reply on a standard form in a prepaid envelope, verifying that their patients had attended for a follow on FP10 prescription. This was done after the first month and after the second month of monitoring, and reminder letters were sent after two weeks. Where possible the non-compliers were contacted to confirm that they had not received a follow on prescription from another source.

Patients on whom details of the follow on prescription had not been recorded in the "take home drugs" book were excluded from the compliance calculations.

The current costs for prescribing antibiotics out of hours were calculated. The calculation took account of the breakdown of patients choosing to see their general practitioner and those opting to return to the hospital pharmacy, and of the primary compliance rates of each group. There is no agreed cost of a general practitioner consultation so the calculation used an estimate of the cost calculated by the pharmaceutical adviser of the Sunderland Health Commission (personal communication). It is recognised that this may be inaccurate but it is the only estimate available.

The costs of providing a full course of antibiotics on the patient's first visit to the A\&E department were calculated and the predicted annual saving deduced. These results are shown in the appendix.

A telephone questionnaire to the 11 largest A\&E departments in Northern Region was also performed to gauge the current practice within the region.

\section{Results}

In the study period of two months, 571 antibiotic items were prescribed to 437 patients. Of these patients, $232(53 \%)$ were recorded as intending to return to the hospital for a follow on prescription or for review and
Table 1 Summary of compliance rates for 437 patients prescribed antibiotics

\begin{tabular}{llll}
\hline & \multicolumn{3}{l}{ Remainder of prescription } \\
\cline { 2 - 4 } & GP & Hospital & Not recorded \\
\hline Numbers (\%) & $176(40 \%)$ & $232(53 \%)$ & $27(7 \%)$ \\
Compliance rate & $46 \%$ & $83.7 \%$ & \\
\hline
\end{tabular}

$176(40 \%)$ had chosen to see their general practitioner. In 29 cases ( $7 \%$ ), the information was not recorded and this group was excluded from further study. The compliance rates are summarised in table 1 . Of the 232 patients intending to return to the hospital, 38 (16.3\%) did not return either for a prescription or for a review appointment. Of the 176 patients who chose to return to their general practitioner, we obtained information on 141 (80\%): $65(46 \%)$ of these patients had returned for a follow on prescription, 71 (50\%) had not returned, and five $(4 \%)$ could not be traced. The age range, median age, and sex distribution between the two groups was almost identical.

We calculated that the current approximate total cost of prescribing out of hours antibiotics each year was $£ 5858$. This includes the cost of the drug itself, the prescription costs, and a costing for the consultation time. It also takes into account the breakdown of those opting to see their general practitioner and those returning to hospital, and the respective compliance rates for each group. The hospital could provide a five day course of antibiotics for $£ 2727$ (annual cost), which is the actual cost of an extra two days' supply of the drugs prescribed. This would generate an approximate saving of $£ 3131$ per year (see appendix).

The telephone questionnaire to the 11 largest $A \& E$ departments in the (old) Northern Region showed that 10 departments already operate a system which dispenses full courses of antibiotics when the pharmacy is closed. However, the two departments (including the study department) which operated the starter pack system accounted for $26 \%$ of the total number of new patients seen by these departments, highlighting the prevalence of the problem. The same questionnaire also revealed an obvious variation in the pharmacy weekend opening hours, with only three pharmacies opening on a Sunday. The pharmacy at one hospital, where the $A \& E$ department sees 42000 new patients a year, did not open at all at weekends, and in another hospital, where the A\&E department supplied starter courses lasting for only one day, the pharmacy was not open every day of the week (table 2) In none of these hospitals were prescription charges collected in the A\&E departments, but this would not directly affect the cost calculations since the income from prescription charges is usually not passed on to the A\&E department.

The conditions for which the antibiotics were prescribed in the hospital primary noncompliers are listed in table 3.

\section{Discussion}

Several studies have looked at primary ${ }^{1-4}$ and secondary compliance. ${ }^{56}$ In this study we are 
Table 2 Results of telephone questionnaire about prescription of antibiotics out of hours

\begin{tabular}{|c|c|c|c|c|}
\hline \multirow[b]{2}{*}{ Hospital } & \multirow{2}{*}{$\begin{array}{l}\text { Size (new } \\
\text { patients) }\end{array}$} & \multirow{2}{*}{$\begin{array}{l}\text { Take home } \\
\text { pack size } \\
\text { (days) }\end{array}$} & \multicolumn{2}{|c|}{$\begin{array}{l}\text { Pharmacy opening hours at } \\
\text { weekends }\end{array}$} \\
\hline & & & Saturday & Sunday \\
\hline \multicolumn{5}{|l|}{ Study } \\
\hline & 66000 & 2 & $8: 30-12: 30$ & \\
\hline A & 65000 & 1 & $9: 00-12: 00$ & \\
\hline B & 40000 & 5 & 9:00-1:00 & \\
\hline C & 35000 & 5 & $9: 00-12: 00$ & $10: 00-1: 00$ \\
\hline D & 29000 & 5 & $9: 30-12: 30$ & $12: 30-1: 30$ \\
\hline $\mathrm{E}$ & 45000 & 5 & $9: 00-1: 00$ & \\
\hline F & 20000 & 5 & $9: 00-12: 30$ & \\
\hline G & 24000 & 5 & $10: 00-12: 00$ & $1: 00-3: 00$ \\
\hline $\mathbf{H}$ & 50000 & 5 & $9: 00-12: 30$ & \\
\hline I & 35000 & 5 & $9: 00-12: 00$ & \\
\hline $\mathrm{J}$ & 42000 & 5 & & \\
\hline $\mathrm{K}$ & 38000 & 5 & $9: 00-12: 00$ & \\
\hline
\end{tabular}

Table 3 Conditions for which hospital non-compliers were prescribed antibiotics

\begin{tabular}{lll}
\hline Condition & $\begin{array}{l}\text { Number of } \\
\text { patients }\end{array}$ & $\begin{array}{l}\text { Prophylaxis (P) } \\
\text { or treatment (T) }\end{array}$ \\
\hline $\begin{array}{l}\text { Animal/human bites } \\
\text { Minor skin infections }\end{array}$ & 10 & $\mathrm{P}$ \\
$\begin{array}{l}\text { Foreign body in hand or } \\
\text { foot }\end{array}$ & 6 & $\mathrm{~T}$ \\
$\begin{array}{l}\text { Lacerations } \\
\text { Webspace infection in }\end{array}$ & 8 & $\mathrm{~T}$ \\
$\quad$ foot & 1 & $\mathrm{P}$ \\
$\begin{array}{l}\text { Abscesses } \\
\text { Postoperative wound }\end{array}$ & 2 & $\mathrm{~T}$ \\
$\quad$ infection & 1 & $\mathrm{~T}$ \\
$\begin{array}{l}\text { Pelvic inflammatory } \\
\text { disease }\end{array}$ & 1 & $\mathrm{~T}$ \\
$\begin{array}{l}\text { Sinusitis/tonsillitis } \\
\text { Ear infection }\end{array}$ & 2 & $\mathrm{~T}$ \\
Compound fracture & 2 & $\mathrm{~T}$ \\
\hline
\end{tabular}

examining a situation where a patient receives medication directly but where the drug dispensed is insufficient for complete treatmentthat is, the initial primary compliance is $100 \%$. However, some patients subsequently fail to collect the remainder of the course and we have termed these patients "late primary noncompliers." In this study, patients who initially chose to obtain the follow on prescription from their general practitioner rather than to return to the hospital pharmacy, were three times more likely to become late primary noncompliers. We are not aware of the previous identification of this subgroup of primary noncompliers, neither are we aware of any studies on the costs of dispensing starter packs from an $\mathrm{A} \& \mathrm{E}$ department.

The study by Freeman and Guly ${ }^{1}$ in 1985 looked at primary compliance in the $A \& E$ department. They found a $16 \%$ primary non-compliance rate for prescriptions issued from their $A \& E$ department, which is identical to the rate we have found for those returning to the hospital pharmacy.

Studies looking at primary non compliance in general practitioner settings found noncompliance rates of $20 \%,{ }^{2} 7 \%,{ }^{3}$ and $6.4 \%{ }^{4}$ These are considerably lower than the $50 \%$ non-compliance found in our study. This might be because patients were prescribed alternative treatment (or none at all) by their general practitioner after being reviewed. It could also be because prescriptions were issued but not recorded, or it may reflect the fact that patients with less severe conditions were not asked to return to A\&E for review; alternatively, the condition may have improved with a three day course of antibiotics and the patient may have elected not to obtain a complete course. A previous study ${ }^{2}$ found that patients with less severe conditions were less likely to get prescriptions dispensed. However, the main reason for the difference is probably that our non-compliance figures reflect late primary non-compliance, where the patient has already been dispensed part of the medication, as opposed to simple primary non-compliance. These are very different measures of primary non-compliance.

The age range of the greatest number of non-compliers $(20 s-30 s)$ is similar to that found in other studies. ${ }^{23}$ The age distribution of non-compliers was similar in both those returning to the hospital pharmacy and those opting to see their general practitioner.

In $38 \%$ of cases the antibiotics were prescribed prophylactically (table 3 ) and one might argue that these patients only need a three day course. However, the majority were prescribed for treatment and it was thought by the senior microbiologist that most needed a five day course. It would be possible to have differing sized courses when dispensing, one for prophylaxis and one for treatment, but this could cause confusion and could be difficult in practice. There is a considerable risk of infection with associated complications in some of the conditions ${ }^{7}$; however, none of the primary non-compliers reattended $A \& E$ with complications during the study period.

The benefits of dispensing a full course of antibiotics to the patient on their first attendance to the $A \& E$ department are that a $100 \%$ primary compliance rate is achieved and late primary non-compliance is avoided. The patient would be saved the inconvenience of reattending the hospital or making an appointment to see their general practitioner. It would stop appointment times being blocked unnecessarily by patients who simply need a follow on prescription and who do not need to be reassessed by a doctor. An FP10 prescription issued to the patient cannot guarantee $100 \%$ primary compliance and is a more expensive way of providing simple antibiotics, since most hospitals are able to buy generic antibiotics in bulk at a cheaper price than the cost to a nonhospital pharmacy.

The only extra cost to the hospital of dispensing five day as opposed to three day courses would be the drug costs for the extra two days, which are minimal. The predicted global cost savings are small but the important point is that an considerable improvement to the system can be made without an apparent cost increase to either the purchasers or the providers. By increasing the antibiotic primary compliance rate to $100 \%$ there is a potential cost saving to the hospital as one could expect fewer complications of untreated infections necessitating admission for intravenous antibiotics and surgical drainage. 
CONCLUSION

The results suggest that a system of dispensing full courses of antibiotics out of hours should be introduced to all $A \& E$ departments. This would have therapeutic advantages to the patient without cost increases to the purchasers. Where starter packs are used, the size of the supply should take account of pharmacy opening hours and hospital holidays.

1 Freeman CP, Guly HR. Do accident \& emergency patients collect their prescribed medication? Arch Emerg Med 1985;2:41-3.

2 Rashid A. Do patients cash prescriptions? BMJ 1985;284: 24-6.

3 Waters WH, Gould NV, Lunn JE. Undispensed prescriptions in a mining general practice. BMJ 1976;i:1062-3.

4 Begg D. Do patients cash prescriptions? An audit in one practice. J R College Gen Pract 1984;34:272-4.

5 Blackwell B. Drug therapy: patient compliance. N Engl J Med 1973;289:249-53.

6 Graham J. Improving drug compliance in general practice. J R Coll Gen Pract 1979;29:399-404.

7 Anderson CR. Animal bites. Guidelines to current management. Postgrad Med 1992;1:134-49.

8 Department of Health. England and Wales Drugs Tariff. London: Department of Health, 1994.

\section{Appendix}

Breakdown of cost of full antibiotic course prescribed out of hours

\begin{tabular}{|c|c|}
\hline \multicolumn{2}{|l|}{ (A) Current costs } \\
\hline $\begin{array}{l}\text { Follow on prescription } \\
\text { (a) Hospital (194/232 patients [83.7\%] }\end{array}$ & \\
\hline $\begin{array}{l}\text { compliance) } \\
\text { (b) GP }(81 / 176 \text { patients [ } 46 \%] \text { compliance) }\end{array}$ & $£ 80.05$ \\
\hline Prescription cost $(81 \times £ 1.35)$ & $£ 109.35$ \\
\hline Container cost $(81 \times 5.8 \mathrm{p})$ & $£ 4.69$ \\
\hline Drug $\cos t^{8}$ & $£ 55.90$ \\
\hline GP timet $(81 \times £ 5.60)$ & $£ 453.60$ \\
\hline TOTAL GP COSTS & $£ 623.54$ \\
\hline TOTAL COSTS FOR STARTER PACK & \\
\hline SYSTEM (two months) & $£ 976.33$ \\
\hline TOTAL ANNUAL COSTS & $£ 5858$ \\
\hline (B) Estimated savings & \\
\hline $\begin{array}{l}\text { Average cost per patient to provide extra two days } \\
\text { of antibiotics } \star\end{array}$ & $£ 1.04$ \\
\hline $\begin{array}{l}\text { Extra cost during two months of study period (437 } \\
\text { patients) }\end{array}$ & $£ 454.48$ \\
\hline EXTRA ANNUAL COSTS & $£ 2726.88$ \\
\hline ESTIMATED ANNUAL SAVING & \\
\hline$(£ 5858-£ 2727)$ & $£ 3131$ \\
\hline
\end{tabular}
cation).

\section{Violence and Verbal Abuse against Accident and Emergency Staff}

A one day conference for doctors and nurses in Accident and Emergency

Thursday 22 May 1997

Royal College of Physicians, 11 St Andrew's Place, Regent's Park, London NW1.

For further details, contact:

Mrs J Broomfield, British Association for Accident and Emergency Medicine, The Royal College of Surgeons of England, 35-43 Lincoln's Inn Fields, London WC2A 3PN; tel 0171831 9405; fax 01714050318.

Doctors $£ 50 \quad$ Nurses $£ 30$ 